\title{
Do online support groups influence the well-being of patients with diabetes?
}

\author{
Noelia Herrero; Lluís Mas-Manchón; Frederic Guerrero-Solé
}

How to cite this article:

Herrero, Noelia; Mas-Manchón, Lluís; Guerrero-Solé, Frederic (2019). “Do online support groups influence the well-being of patients with diabetes?". El profesional de la información, v. 28, n. 2, e280209.

https://doi.org/10.3145/epi.2019.mar.09

Article received on November 9, 2018 Approved on March 3, 2019

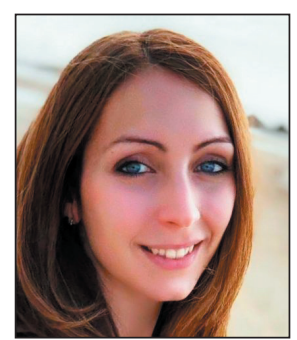

Noelia Herrero $\triangle$ https://orcid.org/0000-0002-7453-4772

Universitat Pompeu Fabra

Roc Boronat, 138. 08018 Barcelona, Spain noelia.herrero@alum.upf.edu

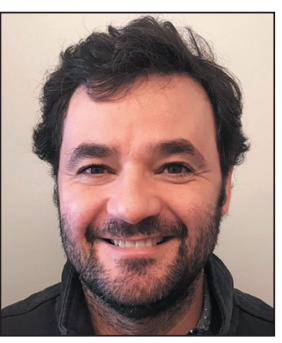

\section{Frederic Guerrero-Solé}

https://orcid.org/0000-0001-8145-8707

Universitat Pompeu Fabra

Roc Boronat, 138. 08018 Barcelona, Spain

frederic.guerrero@upf.edu

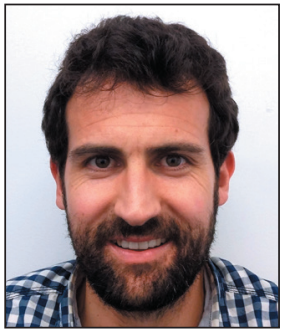

Lluís Mas-Manchón

https://orcid.org/0000-0001-7446-7162

Universitat Pompeu Fabra

Roc Boronat, 138. 08018 Barcelona, Spain

Iluis.mas@upf.edu

\begin{abstract}
Diabetes is one of the most challenging long-term diseases (LTD) nowadays. Diabetes is associated with dietary restrictions, medical treatments and a strict life style, and has important emotional implications. The aim of this study is to analyze the impact of participating in online support groups (OSG) and participants' emotional well-being, social support, self-esteem and motivation. An online survey was disseminated in online forums about diabetes, in Spanish (N = 344). Results show that participating in OSGs has a significant influence on the four variables analyzed. However, the direction of this influence depends on participants' type of diabetes. Participating in OSG is associated with an increase in self-reported social support and motivation for type 2 patients with diabetes, while it is associated with a decrease of both variables for type 1 patients. No differences were observed for emotional well-being and self-esteem. These results have direct implications for both people with type 1 and 2 diabetes and medical professionals in managing online communications more effectively.
\end{abstract}

\section{Keywords}

Diabetes; Online forums; Media effects; Social influence; Emotional well-being; Self-esteem; Social support; Motivation.

\section{Introduction}

Diabetes is one of the most challenging long term diseases (LTD) of our age (Zimmet, 2011). The number of diabetes patients keeps increasing worldwide (Wild et al., 2004). Diabetes is associated with dietary restrictions (regarding sugar or carbohydrates intakes), daily intake of new medication (like metformin), glucose monitoring, insulin injections, and a wide range of health problems and long-term damage (e.g., nephropathy, retinopathy, neuropathy, cardiovascular problems, obesity or amputations) (Rathmann et al., 2018). The overall restrictions, medication treatment and eventual problems sometimes lead to poor diabetes self-management behaviors (Pintaudi et al., 2015) and risks associated with overall health and depression (Anderson et al., 2001; Grigsby et al., 2002; Nicolucci et al., 2013; Holt et al., 2014). 
Diabetes patients are likely to require informational and emotional support. Remarkably, some doctors frame the disease exclusively from a medical standpoint, thus making the patient feel confused or powerless since he or she does not own control on the condition (Thorne; Paterson, 2001). In addition, most patients believe the doctor is not a good option for emotional care because they often lack empathy, trust and a more horizontal interaction (Leimeister; Krcmar, 2005). Although family can give this emotional support and thus enhance the physical and emotional well-being of the diabetic (Ford; Tilley; McDonald, 1998), patients may also benefit from sympathizing with other patients by sharing personal experiences (Kimmerle; Bientzle; Cress, 2014). For this purpose, social media and online settings can be a particularly suitable sphere (Wright, 2002), and a proper use of those may contribute to solve problems related to diabetes and reduce stress (Costanza; Derlega; Winstead, 1988). Conversely, a high emotional burden is associated to a worse diabetes management (Joensen; Almdal; Willaing, 2016). This study aims to find the relations between the participation in an online forum or online support group and the emotional well-being of people with diabetes.

Online support groups (OSGs) increasingly assemble users worldwide, particularly those who suffer from an LTD. Diabetes patients participate in digital communities to share feelings and behaviors related to the disease (Balkhi et al., 2014). Online support groups are a suitable platform for such a personal use because they are easily available, anonymous, and allow selective disclosure and social networking (White; Dorman, 2001). Besides, human beings have a natural inclination to form communities through social networking (Baddeley, 2010). This evolutionary trend has important psychological and social benefits (Christakis; Fowler, 2009).

In general, social bounds and communication are associated with greater emotional stability, lower levels of stress and motivation (Joensen; Almdal; Willaing, 2016; Baumeister; Leary, 2017). Social and emotional bounds can positively affect glucose levels and diabetes self-education (Clark, 2008). This is of great relevance because an improved glycemic control can reduce mortality and obesity from this condition. A study performed to adults with obesity (which is a side effect of diabetes) showed that forum activity is significantly correlated with perceived informational and emotional support. Findings in this study also revealed that females preferred support groups that focused on emotional support, while males preferred those focused on giving information (Reifegerste; Wasgien; Hagen, 2017).

Support groups were first conceived to improve life quality of women with metastatic breast cancer in the 1980's (Spiegel et al., 1989). This kind of support group required the presence of a medical team at a cost that many patients could not afford. Online forums are

"groups of people with common interests and practices that communicate regularly and for some duration in an organized way over the Internet through a common location or mechanism" (Ridings; Gefen; Arinze, 2002, p. 273).

Online support groups are then the combination of support groups and online forums.

Users may participate in online support groups for several reasons, such as to share knowledge in order to show someone's concern for other users, to create a smaller and more homogenous community, or to meet with those that post comments -these comments are usually based on personal experience rather than in expert knowledge (Landqvist, 2016).

The key factors that affect a message's dissemination in online social networks are homophily and social influence (Bakshy et al., 2012). In essence, homophily refers to the users' trend to associate with users who resemble themselves; that is, people flock together with other people that are similar to them, and this breeds connection. Closely related to homophily, social influence is indirect ways of making someone behave or have attitudes in line with the group (Wilson et al., 2016). For instance, a negative emotion towards improving some diabetic's glucose levels can be easily spread in social communities and have an influence on other people with diabetes.

With 1.49 billion daily active users on average, Facebook is the most popular social networking site (Facebook, 2018). Facebook allows the formation of groups of different size that allow people with similar interests to share information and express their opinion around a common cause. Facebook groups can be public, private or secret. Any user should be invited or accepted after a request in order to join a private group. These groups are very similar to an online forum as they allow participants to share their ideas in a post, and other members can answer this post as if it was a thread in a forum. Besides, both Facebook and online forums allow the exchange of private messages between users. In general, Facebook groups and online forums on health issues are thriving (Nieuwboer; Fukkink; Hermanns, 2013).

Aligned with the clear benefits of offline social bounds and communication, online interactions may also have social and emotional positive outcomes. However, a stream of research suggests that online interactions can lead to reduced weII-being because it may lead people to spend more time online than offline, and be detrimental to real social interactions with strong ties like family and close friends (Castellacci; Tveito, 2018). Some studies even suggest that the use of the internet to meet people might also be associated with depression (Boneva et al., 2006).

In essence, on the one hand, being diagnosed with diabetes has a significant emotional impact on the patient to the extent that people with diabetes show a higher prevalence of affective disorders like anxiety, depression and diabetes-re- 
lated distress (Polonsky et al., 2005; Pintaudi et al., 2015; Grigsby et al., 2002). On the other, participants enter online support groups (OSG) to obtain emotional support and information (Smithson et al., 2011). Given this, to what extent do forums help diabetes patients to feel better emotionally? Some studies have analyzed contents in OSGs from both forums and Facebook groups (Al-Mamun; Ibrahim; Turin, 2015; Costa-Sánchez; Míguez-González, 2018; Greene et al., 2011; Makoul et al., 2010), but, to the best of our knowledge, none has tried to confirm if these support groups have an emotional affectation in patients with diabetes. Specifically,

RQ1: Does belonging to a diabetes online social group have an impact on individuals' emotional well-being, including social support, self-esteem, and motivation?

Overall, diabetes is a metabolic disorder characterized by chronic hyperglycemia. Physical and medical differences between diabetes type 1 and 2 are well-reported. Type 1 diabetes is usually called juvenile-onset diabetes (International Diabetes Federation, 2017) because it generally develops in childhood or adolescence. Due to the lack of beta cells in the pancreas, it is always treated with insulin (World Health Organization, 1999). This makes patients with type 1 diabetes to be accustomed to certain conditions from an early stage. On the contrary, type 2 diabetes is a common major form of diabetes in people over 40 years and therefore diagnosed when the patient already has a well-defined life style. Thus, the later has a natural impact on diet, habits and health care in general (International Diabetes Federation, 2017).

Very few studies have focused on the disease's management and emotional state of type 1 and 2 patients. Lin et al. (2017) found that glycemic control has a direct effect on diabetes self-management and indirect effects on depression and diabetes distress through diabetes self-efficacy and diabetes self-management in type 2 diabetes patients. Although depression is associated to both types of diabetes, recent studies have found that factors causing depression may be different for the two types (Vučić-Lovrenčić; Pibernik-Okanović, 2018).

In sum, although today's prevalence of obesity is affecting important segments of children population with type 2 diabetes (Agrawal; Gensure, 2018), type 2 diabetes patients tend to be an older and more heterogeneous segment than type I, with more hypoglycemia and hyperglycemia problems. A side effect of type 2 segment's sociodemographic and lifestyle characteristics is functional impairment and comorbidities -the confluence of different diseases, which may be reasonable to treat individually (Chen et al., 2018). And recent research by Wardian et al. (2018) report that distress and emotional burden associated with diabetes treatments are higher for people with type 2 diabetes:

RQ2. Does the impact of belonging to a diabetes online social group on individuals' emotional well-being, including self-esteem, social support and motivation, depend on the individuals' type of diabetes?

\section{Method and sample}

A cross-sectional study using an online survey was conducted between May $19^{\text {th }}$ to September $6^{\text {th }}$ 2018. The study was approved by the ethical committee of the UPF university. The questionnaire was created in Google Forms. Participants were recruited online via a banner in Dulces Diabéticos's website and through posts in both diabetes online forums and Facebook groups related to diabetes. Participants took as much time as needed in order to complete the survey (an average estimated time of 5 minutes). Only datasets with complete data were analysed. Two participants were excluded from data analyses because they did not provide their consent to participate in the study. 35 more participants were also excluded because they claimed not to have diabetes. The final sample contained 307 participants (mean age: 43,44; SD= 9,45; 49\% men). Their academic degrees included Elementary school (8\%), Secondary School (42\%), Bachelor's Degree (39\%), Master's Degree (7\%), PhD studies (1\%) or none (2\%). 210 participants had Type 2 Diabetes (68\% percent), 82 had Type 1 Diabetes (27\%), and the rest reported having other types of diabetes.

The survey consisted of 4 parts. Firstly, participants were asked to answer questions related to diabetes and their behavior as patients, including the age of diagnosis and the medications being taken. Afterwards, the second set of questions referred to the use of the Internet, the belonging to online social groups and the reasons why they belonged to these groups.

$68.1 \%$ were members of OSGs related to diabetes, while

$39.1 \%$ were not.

Among those who were members of OSGs,

$90.8 \%$ were members of a Facebook group,

$41.5 \%$ of a diabetes-related forum,

$3.9 \%$ of a health related forum and, finally,

$1.4 \%$ were members of other online forums.

$4.3 \%$ of them had been members of online forums for less than 6 months, $58.9 \%$ between 6 months and 3 years, and

$36.7 \%$ for more than 3 years.

The third sets of questions refer to self-care. And, finally, the last set of questions refer to support-seeking (5 items, $M=3.62 ; S D=0.64$; Cronbach's alpha=0.66), perceived well-being (6 items, $M=3.70 ; S D=0.75$; Cronbach's alpha=0.83), self-esteem ( 7 items, $M=3.90 ; S D=0.57$; Cronbach's alpha=0.80), and motivation ( 3 items, $M=3.94 ; S D=0.81 ; C r o n b a c h ' s$ 
alpha $=0.86)$. Cronbach's alpha for the whole scale was equal to 0.78 .

Users were targeted in a diabetes online forum (Diabetes Foro), Dulces Diabeticos' website and posts in several diabetes support groups among Facebook users. The posts were not addressed to anyone in special but specified that the study was addressed to people with diabetes, and therefore any person willing to participate could freely do it, anywhere, anytime.

https://www.diabetesforo.com

https://www.dulcesdiabeticos.com

The independent variable, the online behavior of participants when engaging in social groups, was reported on a Likert scale ranging from 1 (daily) to 5 (never) following these statements:

- "the use of internet",

- "the use of social networking sites",

- "access to sites about health", and

- "comment or share information related to your health in SNS" (Giménez-Pérez et al., 2016; Suziedelyte, 2012).

Users were also asked whether they belonged or not to an online diabetes group and why (Grande; Myers; Sutton, 2006; Kelly; Jenkinson; Ziebland, 2013; Stevens; Duttlinger, 1998). Finally, some yes/no questions about health decisions were made (Giménez-Pérez et al., 2016; Kelly; Jenkinson; Ziebland, 2013).

The dependent variables, encompassed within the variable well-being, were measured with 22 items presented in randomized order and rated on a Likert scale ranging from 1 (strongly disagree) to 5 (strongly agree). Well-being as a variable (McDowell, 2006) includes other four dependent variables, namely:

- emotional well-being,

- social support (Cook-Cottone; Guyker, 2014; Grande; Myers; Sutton, 2006; Stevens; Duttlinger, 1998),

- motivation (Kelly; Jenkinson; Ziebland, 2013), and

- self-esteem (Lyubomirsky; Lepper, 1999; McDowell, 2006; Rosenberg, 1965).

First, emotional well-being is the emotional quality of an individual's everyday experience, which includes the frequency and intensity of experiences of joy, sadness, anger, stress, and affection that make someone's life pleasant or unpleasant (Kahneman; Deaton, 2010), and is measured with statements such as

- "In general, I feel good physically and mentally",

- "In the last month I have been nervous",

- "I feel that I have full control over my behavior, thoughts, emotions, or feelings", or

- "During the last month, I have felt depressed"

adapted from Dupuy (1978) and Fazio (1977).

Second, social support refers to information leading one to believe that he or she is cared for, esteemed, loved, and a member of a social network of mutual obligations (Cobb, 1976), adapted from Mindful Self-care Scale (Cook-Cottone, 2016) and two items from Carpenter (2012), -namely seek and provide support to others-, and includes statements such as

- "I am a person who seeks support in others",

- "I am a person who offers support to others",

- "I feel supported by my relatives" or

- "I feel supported by my friends".

Third, motivation is an equivalent term to determination and refers to emotions and motives being able to determine or influence someone's behavior regarding his or her health condition (McClelland, 1987; Kelly; Jenkinson; Ziebland, 2013), and includes statements such as

- "I have been feeling sad in the last month",

- "I learn something new every day",

- "Every day I am more motivated to improve my illness",

- "I feel that diabetes restricts my life",

- "I feel good physically and psychologically",

from the generic item pool to assess the effects of websites with experiential and factual health information validated in Kelly et al. (2013).

And forth, self-esteem (Rosenberg, 1965) is defined as a personality trait which refers to people's evaluations about their own worth, competence and desirability (Konrath, 2014), and includes statements such as

- "I am satisfied with myself",

- "I think I'm a worthwhile person" or

- "I think I have positive qualities". 


\section{Results}

To answer to the first research question about the relationship between belonging to OSGs related to diabetes and emotional well-being, self-esteem and motivation we first performed a bivariate correlation test between these four variables. As it is shown in table 1, all the four variables are positively correlated, and all the correlations are statistically significant.

Afterwards, we performed an anova to test whether the belonging to OSGs (independent variable) had an impact on any of the four variables analyzed.

Since diabetes patients' behavior in OSGs may differ by type of diabetes, we split the sample in two: (1) patients with type 1 diabetes and (2) patients with type 2 diabetes. We then first calculated the anova values for the 4 variables with type of diabetes as the independent (Table 3).

As it is shown in table 3 , the mean scores of support, weII-being, self-esteem and motivation between type 1 and type 2 groups of patients are statistically different. Consequently, we performed the same anova tests for both types of diabetes, with belonging to OSG as the independent variable (tables 4 and 5).

Results in table 4 and 5 show that there are significant differences between both groups when it comes to the impact of belonging to an OSG or not. While in patients with type 2 diabetes belonging to OSGs significantly increase the scores of support and motivation, in patients with type 1 diabetes these scores significantly decrease for those two variables too. On the contrary, no changes are observed for well-being and self-esteem.

To confirm these results, four two-way anovas were conducted to examine the effect of type of diabetes and belonging to an OSG on social support, emotional well-be-
Table 1. Bivariate correlations between support, well-being, self-esteem and motivation

\begin{tabular}{|l|c|c|c|}
\cline { 2 - 4 } \multicolumn{1}{c|}{} & $\mathbf{1}$ & $\mathbf{2}$ & $\mathbf{3}$ \\
\hline Support (1) & & & \\
\hline Well-being (2) & $0.187^{* *}$ & & \\
\hline Self-esteem (3) & $0.322^{* *}$ & $0.655^{* *}$ & \\
\hline Motivation (4) & $0.568^{* *}$ & $0.411^{* *}$ & $0.663^{* *}$ \\
\hline
\end{tabular}

Table 2. Mean values for support, well-being, self-esteem and motivation (standard deviation in parenthesis), and anova for belonging/not belonging to OSG ( $N=304)$.

\begin{tabular}{|l|c|c|c|c|c|}
\cline { 2 - 5 } \multicolumn{1}{c|}{} & \multicolumn{2}{c|}{ Belongs to OSG } & \multirow{2}{*}{ Difference } & \multirow{2}{*}{ F value } & \multirow{2}{*}{ p value } \\
\cline { 2 - 5 } & No & Yes & & \\
\hline Support & $3.50(0.73)$ & $3.70(0.59)$ & 0.20 & 6.006 & 0.015 \\
\hline Well-being & $3.60(0.90)$ & $3.76(0.66)$ & 0.16 & 3.006 & 0.084 \\
\hline Self-esteem & $3.90(0.73)$ & $3.91(0.49)$ & 0.01 & 0.036 & 0.850 \\
\hline Motivation & $3.76(0.89)$ & $4.02(0.76)$ & 0.26 & 7.178 & 0.008 \\
\hline
\end{tabular}

Table 3. Mean values for support, well-being, self-esteem and motivation (standard deviation in parenthesis), and anova for type of diabetes.

\begin{tabular}{|l|c|c|c|c|c|}
\cline { 2 - 5 } \multicolumn{1}{c|}{} & \multicolumn{2}{c|}{ Type of diabetes } & Difference & F value & p value \\
\cline { 2 - 6 } & $\mathbf{1}(\mathbf{N}=\mathbf{8 3})$ & $\mathbf{2}(\mathbf{N}=\mathbf{2 1 0})$ & & 5.237 & 0.023 \\
\hline Support & $3.48(0.85)$ & $3.68(0.54)$ & -0.20 & 40.405 & 0.000 \\
\hline Well-being & $3.27(1,00)$ & $3.85(0.54)$ & -0.58 & 8.729 & 0.003 \\
\hline Self-esteem & $3.74(0.74)$ & $3.96(0.46)$ & -0.22 & 28.952 & 0.000 \\
\hline Motivation & $3.54(1.05)$ & $4.09(0.65)$ & -0.55 & & \multirow{2}{*}{} \\
\hline
\end{tabular}

Table 4. Mean values for support, well-being, self-esteem and motivation (standard deviation in parenthesis), and anova for belonging/not belonging to OSG for type 1 diabetes $(\mathrm{N}=83)$.

\begin{tabular}{|l|c|c|c|c|c|}
\cline { 2 - 5 } \multicolumn{1}{c|}{} & \multicolumn{2}{c|}{ Belongs to OSG } & \multirow{2}{*}{ Difference } & F value & \multirow{2}{*}{ p value } \\
\cline { 2 - 5 } & No & Yes & & 5.772 & 0.019 \\
\hline Support & $3.80(0.64)$ & $3.33(0.92)$ & -0.47 & 0.888 & 0.349 \\
\hline Well-being & $3.15(1.01)$ & $3.38(0.99)$ & 0.23 & 0.200 & 0.656 \\
\hline Self-esteem & $3.79(0.83)$ & $3.71(0.72)$ & -0.08 & 4.147 & 0.045 \\
\hline Motivation & $3.85(0.86)$ & $3.35(1.11)$ & -0.50 & 0.045 \\
\hline
\end{tabular}

Table 5. Mean values for support, well-being, self-esteem and motivation (standard deviation in parenthesis), and anova for belonging/not belonging to OSG for type 2 diabetes ( $N=210)$.

\begin{tabular}{|l|c|c|c|c|c|}
\cline { 2 - 4 } \multicolumn{1}{c|}{} & \multicolumn{2}{c|}{ Nelongs to OSG } & \multirow{2}{*}{ Difference } & \multirow{2}{*}{ F value } & \multirow{2}{*}{ p value } \\
\cline { 2 - 5 } & No & Yes & & \\
\hline Support & $3.35(0.76)$ & $3.82(0.34)$ & 0.47 & 36.269 & 0.000 \\
\hline Well-being & $3.78(0.78)$ & $3.89(0.41)$ & 0.11 & 1.660 & 0.199 \\
\hline Self-esteem & $3.93(0.67)$ & $3.98(0.35)$ & 0.05 & 0.382 & 0.537 \\
\hline Motivation & $3.70(0.92)$ & $4.26(0.40)$ & 0.56 & 36.706 & 0.000 \\
\hline
\end{tabular}


ing, self-esteem and motivation. We found again a statistically significant interaction of the independent variables on support $[F(1,281)=29.552, p=0.000]$ and motivation $[F(1,281)=25.257, p=0.000]$, and no significant interaction for emotional well-being and self-esteem (Figure 1).
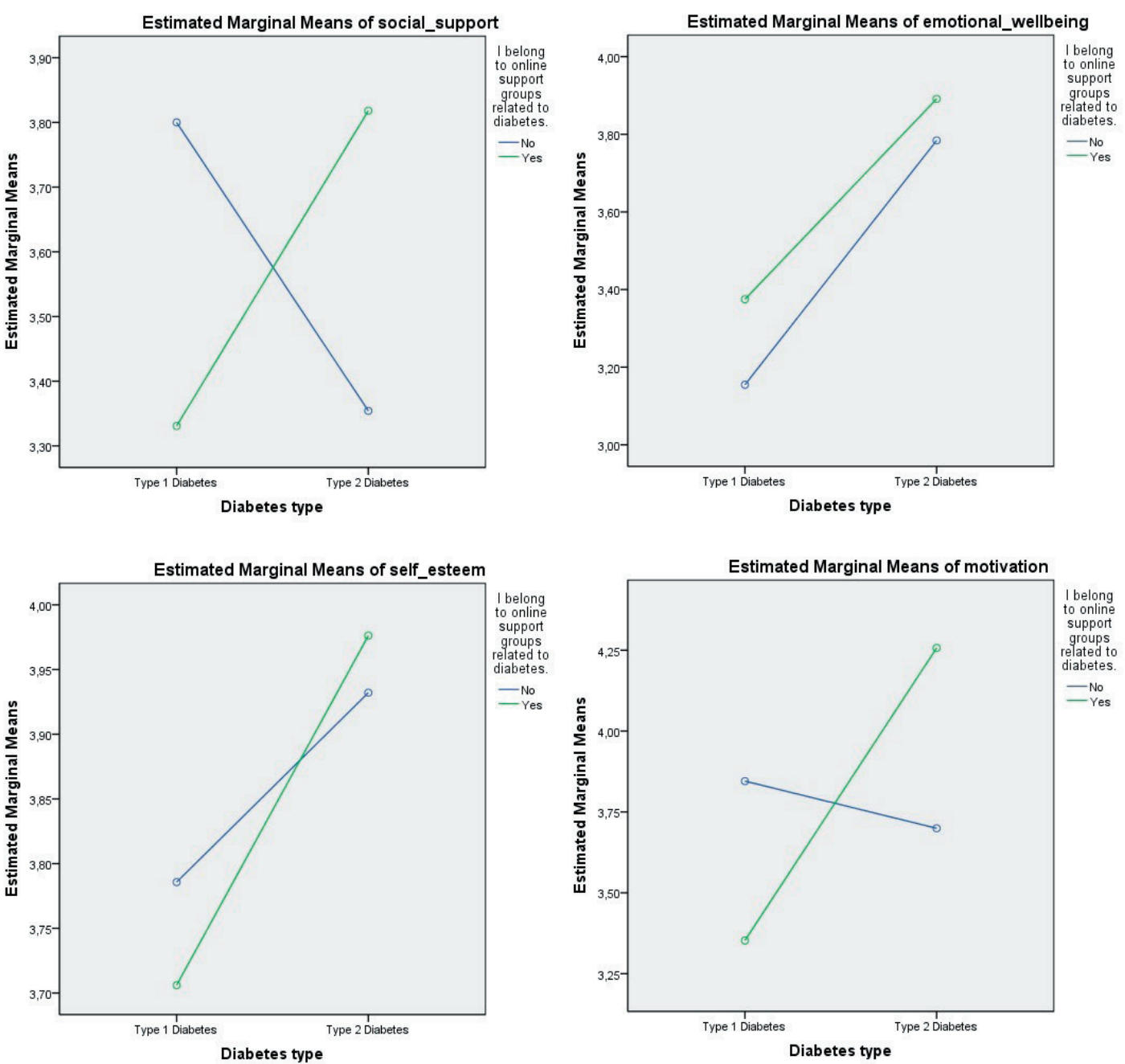

Figure 1. Plots of the estimated marginal means for the effect of belonging to OSG and type of diabetes on social support, emotional well-being, selfesteem and motivation.

\section{Discussion}

Our results show that belonging to OSG has a positive influence on social support and motivation experienced by people with diabetes. Having a direct connection between belonging to OSG and social support has a straightforward discussion: OSG foster social contact with other people with diabetes and this is a direct way of being supported. With regard to motivation and self-esteem, the former refers to the state of the individual with regard to the community or society whereas the latter is a more introspective variable that refer to the individual. OSG are used to build a community of people with diabetes but have no influence on the patient's assessment/concept of himself/herself.

Therefore, in line with previous research, support groups contribute to emotional stability, lower the levels of stress and increase motivation (Joensen; Almdal; Willaing, 2016; Baumeister; Leary, 2017). Arguably, this finding reinforces the emotional benefits of communicating and holding social bonds with peers. However, the fact that these social bonding and communication takes places online adds insights to this process. Particularly, the mechanisms of social influence and homophily are crucial in OSG and should be discussed as determinants of these findings.

However, our research found that there exist significant opposed differences between the two types of diabetes regarding social support and motivation.

While for people with Type 1 diabetes belonging to OSG has a negative impact on social support and motivation, the impact for people with Type 2 diabetes is significantly positive, as it is the impact on self-esteem and emotional well-being. These findings reinforce all said for the type Being diagnosed with diabetes has a sig2 diabetes patients, and puts the focus on the emotionificant emotional impact on the patient 
nal, social and individual benefits of OSG on people with type 2 diabetes. As pointed out, researchers are aware that types 1 and 2 have rather different impact on the physical and emotional condition of patients (Wardian et al., 2018). Despite the lack of research on how the benefits of social bonds and communication may be specific to the types of diabetes, we found OSG to have stronger impact on the type 2 diabetic's well-being. Type 2 patients are expected to have more problems to deal with the disease, as they should accustom their lifestyle in general. In this line, some studies have already reported greater difficulties for managing the disease, depression and instability (Lin et al., 2017; Wardian et al., 2018).

Our findings point to clear differences in the social and emotional requirements of diabetes type 1 and 2 . They rather seem different diseases or, at the least, with different emotional implications. There is a gap of knowledge to be filled here in forthcoming studies. Anyhow, results call for further research on the impact of OSG for people with type 1 and 2 diabetes, as the former are not clearly gaining benefits from it.

\section{Conclusions}

This study evidences the differences of the impact of belonging to OSG self-reported social support and motivation between people with type 1 and type 2 diabetes. OSG increases the means of both variables for type 2, and decreases them for type 1. No differences were observed for emotional well-being and self-esteem. These results may assist both diabetes patients and medical professionals in managing online communications and resources more effectively, in particular, when patients seek social support from others that are more experienced in the diabetes field.

This study is not without limitations. First, the quantitative nature of the study has important limitations, specifically the use of self-reported scales. Some qualitative approaches may help gain insights into the impact of online social groups. Second, the sample of type 1 and 2 participants is unequal (27\% of the sample were type 1 ), probably because OSG are heterogeneous and type 1 represents less than 10\% of people with diabetes (International Diabetes Federation, 2017). Further investigation should take this into account.

\section{References}

Agrawal, Sungeeta; Gensure, Robert (2018). "Commentary on the impact of obesity on pediatric diabetes". Clinical therapeutics, v. 40, n. 10, pp. 1631-1637.

https://doi.org/10.1016/j.clinthera.2018.08.006

Al-Mamun, Mohammad; Ibrahim, Hamza, M.; Turin, Tanvir-Chowdhury (2015). "Social media in communicating health information: An analysis of Facebook groups related to hypertension". Preventing chronic disease, v. 12. https://doi.org/10.5888/pcd12.140265

Anderson, Ryan J.; Freedland, Kenneth E.; Clouse, Ray L.; Lustman, Patrick J. (2001). "The prevalence of comorbid depression in adults with diabetes: a meta-analysis". Diabetes care, v. 24, n. 6, pp. 1069-1078.

https://doi.org/10.2337/diacare.24.6.1069

Baddeley, Michelle (2010). "Herding, social influence and economic decision-making: Socio-psychological and neuroscientific analyses". Philosophical transactions of the Royal Society of London B: Biological Sciences, v. 365, n. 1538, pp. 281-290.

https://doi.org/10.1098/rstb.2009.0169

Bakshy, Eytan; Rosenn, Itamar; Marlow, Cameron; Adamic, Lada (2012). "The role of social networks in information diffusion". In: Proceedings of the 21 st intl conf on World Wide Web. USA: ACM. ISBN: 9781450312295

https://doi.org/10.1145/2187836.2187907

Balkhi, Amanda M.; Reid, Adam M.; McNamara, Joseph P. H.; Geffken, Gary R. (2014). "The diabetes online community: the importance of forum use in parents of children with type 1 diabetes". Pediatric diabetes, v. 15, n. 6, pp. 408-415. https://doi.org/10.1111/pedi.12110

Baumeister, Roy F.; Leary, Mark R. (2017). “The need to belong: Desire for interpersonal attachments as a fundamental human motivation". In: Zukauskiene, Rita. Interpersonal development. Routledge. ISBN: 9781351153676 https://doi.org/10.4324/9781351153683-3

Boneva, Bonka S.; Quinn, Amy; Kraut, Robert; Kiesler, Sara; Shklovski, Irina (2006). "Teenage communication in the instant messaging era". In: Kraut, Robert; Brynin, Malcom; Kiesler, Sara. Computers, phones and the internet: Domesticating information technology. OxFord Scholarship Online. ISBN: 9780195312805 https://doi.org/10.1093/acprof:oso/9780195312805.003.0014

Castellacci, Fulvio; Tveito, Vegard (2018). "Internet use and well-being: A survey and a theoretical framework". Research policy, v. 47, n. 1, pp. 308-325.

https://doi.org/10.1016/j.respol.2017.11.007 
Chen, Wei-Che; Lee, Chun-Chua; Chien, Ming-Nan; Liu, Sung-Chen; Wang, Chao-Hung; Yang, Wei-Shiung (2018). "Blood glucose management of type 2 diabetes in the older people". International journal of gerontology, v. 12, n. 3, pp. $170-174$. https://doi.org/10.1016/j.ijge.2018.05.008

Christakis, Nicholas A.; Fowler, James H. (2009). Connected: The surprising power of our social networks and how they shape our lives. USA: Little, Brown. ISBN: 9780316036146

Clark, Marie (2008). “Diabetes self-management education: a review of published studies". Primary care diabetes, v. 2 , n. 3, pp. 113-120.

https://doi.org/10.1016/j.pcd.2008.04.004

Cobb, Sidney (1976). "Social support as a moderator of life stress". Psychosomatic medicine, v. 38, n. 5, pp. $300-314$. https://doi.org/10.1097/00006842-197609000-00003

Cook-Cottone, Catherine P.; Guyker, Wendy M. (2014). "The Mindful self-care scale: Self-care as a tool to promote physical, emotional, and cognitive well-being". PsycTests dataset.

https://doi.org/10.1037/t66058-000

Costa-Sánchez, Carmen; Míguez-González, María-Isabel (2018). “Use of social media for health education and corporate communication of hospitals". El profesional de la información, v. 27, n. 5, pp. 1145-1154.

https://doi.org/10.3145/epi.2018.sep.18

Costanza, Robert S.; Derlega, Valerian J.; Winstead, Barbara A. (1988). "Positive and negative forms of social support: Effects of conversational topics on coping with stress among same-sex friends". Journal of experimental social psychology, v. 24, n. 2, pp. 182-193.

https://doi.org/10.1016/0022-1031(88)90020-0

Dupuy, Harold J. (1978). "General well-being schedule". PsycTests dataset. https://doi.org/10.1037/t04083-000

Facebook Newsroom. Stats. https://newsroom.fb.com/company-info

Fazio, Anthony F. (1977). "A concurrent validational study of the NCHS General well-being schedule". PsycExtra dataset [Internet]. American Psychological Association (APA).

https://www.cdc.gov/nchs/data/series/sr_02/sr02_073.pdf

Ford, Marvella E.; Tilley, Barbara C.; McDonald, Patricia E. (1998). "Social support among African-American adults with diabetes. Part 1: Theoretical framework". Journal of the National Medical Association, v. 90, n. 6, pp. 361-365.

https://www.ncbi.nlm.nih.gov/pmc/articles/PMC2568240

Giménez-Pérez, Gabriel; Recasens, Assumpta; Simó, Olga; Aguas, Teresa; Suárez, Ana; Vila, Maria; Castells, Ignasi (2016). "Use of communication technologies by people with type 1 diabetes in the social networking era. A chance for improvement". Primary care diabetes, v. 10, n. 2, pp. 121-128.

https://doi.org/10.1016/j.pcd.2015.09.002

Grande, Gesine E.; Myers, Lynn B.; Sutton, Stephen R. (2006). “How do patients who participate in cancer support groups differ from those who do not?". Psycho-oncology: Journal of the psychological, social and behavioral dimensions of cancer, v. 15, n. 4, pp. 321-334.

https://doi.org/10.1002/pon.956

Greene, Jeremy A.; Choudhry, Niteesh K.; Kilabuk, Elaine; Shrank, William H. (2011). “Online social networking by patients with diabetes: a qualitative evaluation of communication with Facebook". Journal of general internal medicine, $\mathrm{v}$. 26, n. 3, pp. 287-292.

https://doi.org/10.1007/s11606-010-1526-3

Grigsby, Allison B.; Anderson, Ryan J.; Freedland, Kenneth E.; Clouse, Ray E.; Lustman, Patrick J. (2002). "Prevalence of anxiety in adults with diabetes: A systematic review". Journal of psychosomatic research, v. 53, n. 6, pp. 1053-1060. https://doi.org/10.1016/S0022-3999(02)00417-8

Holt, Richard I. G.; De-Groot, Mary; Hill-Golden, Sherita (2014). "Diabetes and depression”. Current diabetes reports, v. 14, n. 6, pp. 491.

https://doi.org/10.1007/s11892-014-0491-3

International Diabetes Federation (2017). Types of diabetes.

https://www.idf.org/aboutdiabetes/what-is-diabetes.html

Joensen, Lene E.; Almdal, Thomas P.; Willaing, Ingrid (2016). "Associations between patient characteristics, social relations, diabetes management, quality of life, glycaemic control and emotional burden in type 1 diabetes". Primary care diabetes, v. 10, n. 1, pp. 41-50. 
Kahneman, Daniel; Deaton, Angus (2010). "High income improves evaluation of life but not emotional well-being". In: Procs of the National Academy of Sciences of the United States of America, v. 107, n. 38, pp. 16489-16493. https://doi.org/10.1073/pnas.1011492107

Kelly, Laura; Jenkinson, Crispin; Ziebland, Sue (2013). "Measuring the effects of online health information for patients: Item generation for an e-health impact questionnaire". Patient education and counseling, v. 93, n. 3, pp. $433-438$. https://doi.org/10.1016/j.pec.2013.03.012

Kimmerle, Joachim; Bientzle, Martina; Cress, Ulrike (2014). “Personal experiences and emotionality in health-related knowledge exchange in internet forums: A randomized controlled field experiment comparing responses to facts vs personal experiences". Journal of medical internet research, v. 16, n. 12.

https://doi.org/10.2196/jmir.3766

Konrath, Sara H. (2014). "Self-esteem, culturally defined". Cultural sociology of mental illness: An A-to-Z guide. Sage reference.

https://doi.org/10.4135/9781483346342.n286

Landqvist, Mats (2016). "Sense and sensibility-online forums as epistemic arenas". Discourse, context \& media, v. 13, pp. 98-105.

https://doi.org/10.1016/j.dcm.2016.05.007

Leimeister, Jan-Marco; Krcmar, Helmut (2005). "Evaluation of a systematic design for a virtual patient community". Journal of computer-mediated communication, v. 10, v. 4, JCMC1041.

https://doi.org/10.1111/j.1083-6101.2005.tb00269.x

Lin, Keke; Park, Chang; Li, Mingzi; Wang, Xiudong; Li, Xiushu; Li, Wei; Quinn, Laurie (2017). “Effects of depression, diabetes distress, diabetes self-efficacy, and diabetes self-management on glycemic control among Chinese population with type 2 diabetes mellitus". Diabetes research and clinical practice, v. 131, pp. 179-186.

https://doi.org/10.1016/j.diabres.2017.03.013

Lyubomirsky, Sonja; Lepper, Heidi S. (1999). "A measure of subjective happiness: Preliminary reliability and construct validation". Social indicators research, v. 46, n. 2, pp. 137-155.

https://doi.org/10.1023/a:1006824100041

Makoul, Gregory; Zick, Amanda B.; Aakhus, Mark; Neely, Kathy J.; Roemer, Phillip E. (2010). “Using an online forum to encourage reflection about difficult conversations in medicine". Patient education and counseling, v. 79, n. 1, pp. 83-86. https://doi.org/10.1016/j.pec.2009.07.027

McClelland, David C. (1987). Human motivation. CUP Archive. ISBN: 9780521369510

McDowell, Ian (2006). Measuring health: a guide to rating scales and questionnaires. USA: Oxford University Press. ISBN: 9780195165678

Nicolucci, Antonio; Burns, Katharina-Kovacs; Holt, Richard I.; Comaschi, Marco; Hermanns, Norbert; Ishii, Hitoshi; Kokoszka, Andrzej; Pouwer, Frans; Skovlund, Søren E.; Stuckey, Heather L.; Tarkun, Ilhan; Vallis, Michael; Wens, Johan; Peyrot, Mark (2013). "Diabetes attitudes, wishes and needs second study (DAWN2 ${ }^{\mathrm{TM}}$ ): Cross-national benchmarking of diabetes-related psychosocial outcomes for people with diabetes". Diabetic medicine, v. 30, n. 7, pp. 767-777. https://doi.org/10.1111/dme.12245

Nieuwboer, Christa C.; Fukkink, Ruben G.; Hermanns, Jo M. A. (2013). “Peer and professional parenting support on the internet: a systematic review". Cyberpsychology, behavior, and social networking, v. 16, n. 7, pp. 518-528.

https://doi.org/10.1089/cyber.2012.0547

Pintaudi, Basilio; Lucisano, Giuseppe; Gentile, Sandro; Bulotta, Angela; Skovlund, Soren E.; Vespasiani, Giacomo; Rossi, Maria C.; Nicolucci, Antonio (2015). "Correlates of diabetes-related distress in type 2 diabetes: Findings from the benchmarking network for clinical and humanistic outcomes in diabetes (Bench-D) study". Journal of psychosomatic research, v. 79, n. 5, pp. 348-354.

https://doi.org/10.1016/j.jpsychores.2015.08.010

Polonsky, William H.; Fisher, Lawrence; Earles, Jay; Dudl, R. James; Lees, Joel; Mullan, Joseph; Jackson, Richard A. (2005). "Assessing psychosocial distress in diabetes: Development of the diabetes distress scale". Diabetes care, v. 28, n. 3, pp. 626-631. https://doi.org/10.2337/diacare.28.3.626

Rathmann, Wolfgang; Kuss, Oliver; Anderson, Dörte; Busch, Stefan; Hahn, Michael; Engelhard, Johanna; Zou, Ming; Kostev, Karel (2018). "Increased depression symptom score in newly diagnosed type 2 diabetes patients". Psychiatry research, v. 261, pp. 259-263.

https://doi.org/10.1016/j.psychres.2017.12.091 
Reifegerste, Doreen; Wasgien, Katrin; Hagen, Lutz M. (2017). “Online social support for obese adults: Exploring the role of forum activity". International journal of medical informatics, v. 101.

https://doi.org/10.1016/j.ijmedinf.2017.02.003

Ridings, Catherine M.; Gefen, David; Arinze, Bay (2002). "Some antecedents and effects of trust in virtual communities". The journal of strategic information systems, v. 11, n. 3-4, pp. 271-295.

https://doi.org/10.1016/S0963-8687(02)00021-5

Rosenberg, Morris (1965). "Rosenberg self-esteem scale (RSE)". Acceptance and commitment therapy. Measures package, v. 61, n. 52.

https://doi.org/10.1037/t01038-000

Smithson, Janet; Sharkey, Siobhan; Hewis, Elaine; Jones, Ray; Emmens, Tobit; Ford, Tamsin; Owens, Christabel (2011). "Problem presentation and responses on an online forum for young people who self-harm". Discourse studies, v. 13, n. 4, pp. 487-501.

https://goo.gl/q5aSQJ

https://doi.org/10.1177/1461445611403356

Spiegel, David; Kraemer, Helena C.; Bloom, Joan R.; Gottheil, Ellen (1989). "Effect of psychosocial treatment on survival of patients with metastatic breast cancer". The lancet, v. 334, n. 8668, pp. 888-891.

https://doi.org/10.1016/S0140-6736(89)91551-1

Stevens, Michael J.; Duttlinger, Jorie E. (1998). "Correlates of participation in a breast cancer support group". Journal of psychosomatic research, v. 45, n. 3, pp. 263-275.

https://doi.org/10.1016/S0022-3999(97)00296-1

Suziedelyte, Agne (2012). "How does searching for health information on the internet affect individuals' demand for health care services?". Social science \& medicine, v. 75, n. 10, pp. 1828-1835.

https://doi.org/10.1016/j.socscimed.2012.07.022

Thorne, Sally E.; Paterson Barbara L. (2001). "Health care professional support for self-care management in chronic illness: insights from diabetes research". Patient education and counseling, v. 42, n. 1, pp. 81-90.

https://doi.org/10.1016/S0738-3991(00)00095-1

Vučić-Lovrenčić, Marijana; Pibernik-Okanović, Mirjana (2018). “Longitudinal associations between biomarkers of inflammation and changes in depressive symptoms in diabetic patients". Psychoneuroendocrinology, v. 93, pp. 117.

https://doi.org/10.1016/j.psyneuen.2018.04.011

Wardian, Jana L.; Tate, Joshua; Folaron, Irene; Graybill, Sky; True, Mark; Sauerwein, Tom (2018). “Who's distressed? A comparison of diabetes-related distress by type of diabetes and medication". Patient education and counseling, v. 101, n. 8, pp. 1490-1495.

https://doi.org/10.1016/j.pec.2018.03.001

White, Marsha; Dorman, Steve M. (2001). "Receiving social support online: implications for health education". Health education research, v. 16, n. 6, pp. 693-707.

https://doi.org/10.1093/her/16.6.693

Wild, Sarah; Roglic, Gojka; Green, Anders; Sicree, Richard; King, Hilary (2004). "Global prevalence of diabetes: estimates for the year 2000 and projections for 2030". Diabetes care, v. 27, n. 5, pp. 1047-1053.

https://doi.org/10.2337/diacare.27.5.1047

Wilson, Kelly-Schwind; DeRue, D. Scott; Matta, Fadel K.; Howe, Michael; Conlon, Donald E. (2016). "Personality similarity in negotiations: Testing the dyadic effects of similarity in interpersonal traits and the use of emotional displays on negotiation outcomes". Journal of applied psychology, v. 101, n. 10, pp. 1405.

https://doi.org/10.1037/ap/0000132

World Health Organization (1999). Definition, diagnosis and classification of diabetes mellitus and its complications: report of a WHO consultation. Part 1, Diagnosis and classification of diabetes mellitus. Geneva: World Health Organization. http://www.who.int/iris/handle/10665/66040

Wright, Kevin (2002). "Social support within an on-line cancer community: An assessment of emotional support, perceptions of advantages and disadvantages, and motives for using the community from a communication perspective". Journal of applied communication research, v. 30, n. 3, pp. 195-209.

https://doi.org/10.1080/00909880216586

Zimmet, Paul Z. (2011). "The growing pandemic of type 2 diabetes: a crucial need for prevention and improved detection". Medicographia, v. 3, n. 1, pp. 15-21.

https://www.medicographia.com/2011/07/the-growing-pandemic-of-type-2-diabetes-a-crucial-need-for-preventionand-improved-detection 